ÜNIVERSITE ÖĞRENCILERININ VÜCUT SEGMENTLERINNE GÖRE YAĞ VE KAS ORANLARININ AEOROBIK, ANAEROBIKK VE ESNEKLİK PARAMETRELERIYYL ILIŞKISII (1)

\title{
INVESTIGATION OF BODY FAT AND BODY MUSCLE PROPORTION OF PHYSICAL EDUCATION AND SPORT STUDENTS BY SOME MO- TORIC FEATURES
}

\author{
Sevde MAVI VAR
}

Kırşehir Ahi Evran Üniversitesi, Beden Eğitimi ve Spor Yüksekokulu, Kırşehir / Türkiye

ORCID ID: 0000-0002-0767-0985

Öz: Amaç: Bu araștırmanın amacı beden eğitimi ve spor yüksekokulu öğrencilerinin vücut segmentlerine göre vücut yağ ve kas oranlarının aerobik, anaerobik ve esneklik özellikleriyle arasındaki ilişkinin belirlenmesidir. Yöntem: Çalışmaya Ahi Evran Üniversitesi Beden Eğitimi ve Spor Yüksekokulunda öğrenim gören 18 kadın, 13 erkek olmak üzere toplam 31 öğrenci katılmıştır. Çalışmaya katılan öğrencilerin vücut kompozisyonları bioelektrik impedans (BIA) analiz yöntemiyle belirlenmiş̧tir. Aerobik kapasitelerini belirleyebilmek için Cooper testi, anaerobik kapasitelerini belirleyebilmek amacıyla 30 metre sprint testi ve dikey sıçrama testi, esneklik özelliklerini belirleyebilmek amacıyla ise otur-uzan testi uygulanmıştır. Bulgular: Bulgular incelendiğinde erkeklerde dikey sıçrama ve sol bacak kas arasında $(r=-, 718, p<0.01)$, negatif yönlü yüksek düzeyde anlamlı bir ilişki, $30 \mathrm{~m}$ sürat ve kas kütlesi arasında $(\mathrm{r}=, 642, \mathrm{p}<0.05)$, pozitif yönlü orta düzeyde anlamlı bir ilişki olduğu görülmüștür. Kadınlarda ise performans parametreleri ile vücut segmentleri arasında anlaml bir ilişkiye rastlanamamıştır. Sonuç: Sonuç olarak erkeklerin vücut segmentlerine göre kas kütleleri ve yağ yüzdeleri açısından aerobik ve anaerobik kapasiteleri arasında bir ilişki olduğu görülmüștür. Kadınlarda ise vücut segmentlerine göre kas ve yağ oranları incelendiğinde kas oranlarının düşük, yağ oranlarının yüksek olduğu ve bundan dolayı aerobik ve anaerobik kapasitelerinin düşük olduğu söylenebilir.

Anahtar Kelimeler: Vücut Yağ ve Kas Oranı, Aerobik Performans, Anaerobik Performans, Esneklik
Abstract: Aim: The aim of this study was to determine the relationship between aerobic, anaerobic and flexbility properties of body fat and muscle ratios according to body segments of physical education and sports students. Method:A total of 31 students (18 female and 13 male) were studying at Ahi Evran University School of Physical Education and Sports participated in the study. The body compositions of the students were determined by bioelectric impedance (BIA) analysis. In order to determine aerobic capacity Cooper test, to determine the anaerobic capacities of 30 meters sprint test and vertical jump test, and to determine the flexibility sit-reach test was used in the study. Results: When the findings were examined, a high level of negative correlation was found between the vertical jump and the left leg muscle $(r=-, 718, p<0.01)$ and there was a moderate positive correlation between $30 \mathrm{~m}$ sprint and muscle mass $(r=642, p<0.05)$. There was no significant relationship was found between performance parameters and body segments for women. Conclusion: As a result, there was a relationship between aerobic and anaerobic capacities of muscle masses and fat percentages of males according to body segments. When the muscle and fat ratios were examined according to the body segments in women, it was possible to say that the muscle ratios were low and the fat ratios were high and therefore the aerobic and anaerobic capacities were low.

Key Words: Body Fat and Muscle Propotion, Aerobik Performance, Anaerobic Performance, Flexibility

Doi: 10.17363/SSTB.2018.29.4

(1) Sorumlu Yazar: Sevde MAVİ VAR, Kırşehir Ahi Evran Üniversitesi, Beden Eğitimi ve Spor Yüksekokulu, Kırşehir /Türkiye, sevde.mavivar@ahievran.edu.tr, Geliş Tarihi/Received: 19.08.2018, Kabul Tarihi/Accepted: 18.12.2018, Makalenin Türü: Type of article (Araştırma - Uygulama / Research -Application) Çıkar Çatısması / Conflict of Interest: Yok / None Etik Kurul Raporu/Ethics Committee: Yok / None 
International Refereed Academic Journal of Sports, Health and Medical Sciences October - November - December Issue: 29 Fall Winter Semester Year: 2018

Uluslararası Hakemli Akademik Spor Sağlık ve Tıp Bilimleri Dergisi Ekim - Kasım - Aralık Sayı: 29 Güz Kış Dönemi Yıl: 2018 ID:410 K:318

ISSN Print: 2146-8508 Online 2147-1711

(ISO 18001-OH-0090-13001706 / ISO 14001-EM-0090-13001706 / ISO 9001-QM-0090-13001706 / ISO 10002-CM-0090-13001706) (TRADEMARK)

\section{GíRiş}

Spor bilimleri alanında ilk zamanlardan bu yana farklı tartışma ve yorumlara neden olan vücut kompozisyonu ile fiziksel aktivite arasındaki ilişki spor bilimcilerinin sürekli merak ettiği bir konu olmasından dolayı bu konuyla ilgili durum değerlendirmesi, karş1laştırmalar ya da performansla ilişkilendirilmesi boyutunda araştırmalar yapılmaktadır. Literatür tarandığında vücut kompozisyonu ile performans ilişkisi arasında birçok çalışma olmasına rağmen bu araştırmanın temel amacını oluşturan vücut segmentlerine göre performans ilişkisini içeren çok az araştırmaya rastlanmaktadır. Bu nedenle vücut segmentlerine göre aerobik, anaerobik ve esneklik parametrelerinin arasındaki ilişkiyi inceleyen bu çalışma literatüre katkı sağlayabilir.

Günümüzde vücut kompozisyonunu belirleyebilmek için biyoelektriksel impedans analizi (BIA) en gelişmiş ve yaygın olarak kullanılan tekniklerden biridir. BIA ölçümü diğer vücut kompozisyon ölçüm yöntemleriyle kıyaslandığında daha pratik ve ucuz bir yöntemdir (Baumparter ve diğ., 1998; Ellis ve diğ., 1999). Biyoelektrik impedans analizindeki impedans dokunun iletkenlikle ters orantılı olarak elektrik akımına gösterdiği dirençten kaynaklanmaktadır. Bu yöntemde dokudan geçirilen düşük voltajlı elektrik ak1mıyla dokulardaki sıvı kütlesi ile ters orantılı olan impedans ölçülür. BİA yönteminin te- melinde yatan prensip, kemik ve yağ dokusu gibi direnci yüksek bileşenlerin elektrik akımı geçişini zorlaştırmasıyla iç organlar ve iskelet kası gibi düşük dirençli bileşenlerin elektrik akımının kolayca geçmesi olayından kaynaklanmaktadır (Martelletti ve diğ., 1991, Mialich ve diğ., 2014) Vücut kompozisyonunun segmental olarak değerlendirilmesi egzersiz, hastalık ya da travmaların etkilerini görebilmek açısından oldukça önemli bir değerlendirmedir (Hughes, 1997).

İnsan organizmanın fizyolojik aktivitesi ile yakın olarak ilişkili olan antropometrik özellikler sporda başarıyı belirleyici faktörler arasında olduğu söylenebilir (Sınırkavak ve diğ., 2004, Zorba ve Saygın, 2009). Sporda başar1y1 getiren en önemli unsurlardan olan kuvvet, dayanıklılık, sürat gibi temel motorik özelliklerle beraber bireyin performans durumunun izlenebilmesi için antropometrik ölçümlerle yapılan bilimsel temelli yetenek seçimleri oldukça önemlidir (Erdoğan ve diğ., 2018).

Aerobik ve anaerobik kapasite; yaş, cinsiyet, genetik faktörler, fizyolojik özellikler, antrenman seviyesi ve vücut kompozisyonu olmak üzere birçok faktörden etkilenmektedir (Çağlar ve diğ., 1997, Yıldız, 2012). Aerobik kapasite, egzersiz sırasında gerekli enerjiyi oluşturmak için kullanılacak oksijeni kaslara verebilme kapasitesi olarak tanımlanabilmektedir (Yildiz, 2012). Aerobik kapasite veya aerobik güç, maksimal oksijen iletimi ve kas 


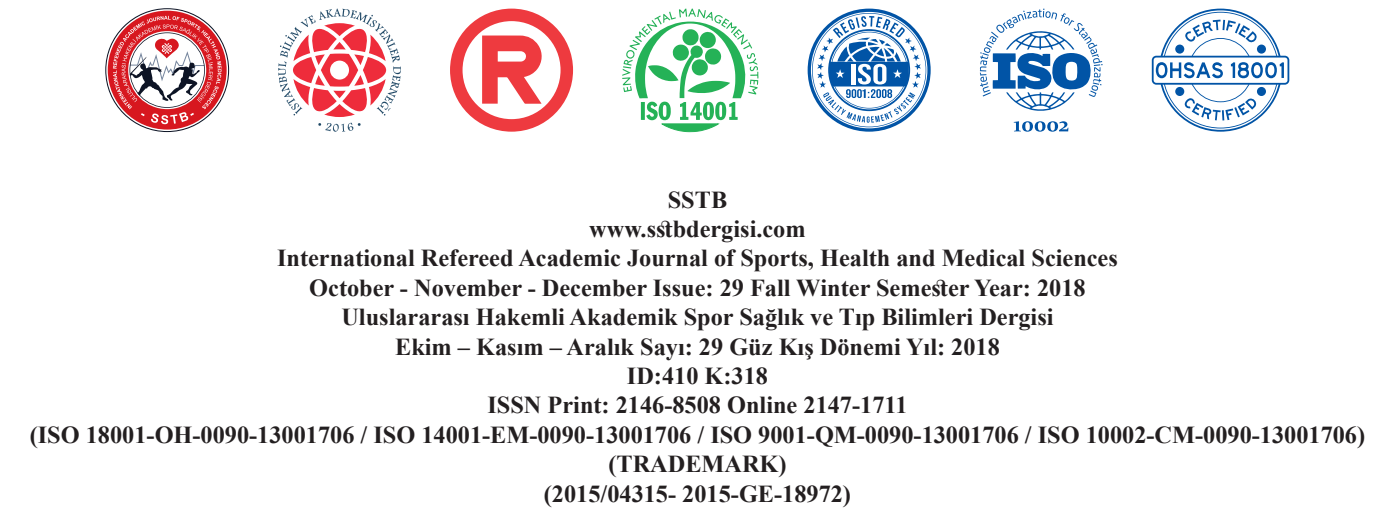

dokusunun oksijen kullanım kapasitesini ifade eder (Günay ve diğ., 2006). Aerobik güç ayrıca, kardiyovasküler sistem kapasitesinin önemli bir indeksidir (Nagle, 1973). Anaerobik kapasite ise maksimal ve submaksimal fiziksel aktivite sırasında iskelet kaslarının anaerobik enerji transfer sistemlerini kullanarak meydana getirdiği iş kapasitesi olarak tanımlanmaktadır (Jonathan, 1997).

Aerobik kapasite ve anaerobik kapasite birçok spor branşında performansı oldukça etkileyen önemli özelliklerdir. Bu özellikler genetik olmasıyla beraber kişinin düzeyi ve yaptığı antrenmanlarla da yakından ilişsilidir. Vücut kompozisyonlarını belirleyerek ve segmental olarak ta inceleme yapilarak bu motorik özelliklerin değerlendirilmeleri yapilabilir.

Bu bilgiler 1şığında bu çalışmada beden eğitimi ve spor yüksekokulu öğrencilerinin vücut segmentlerine göre vücut kas ve yağ oranları belirlenerek aerobik, anaerobik ve esneklik performanslarıyla ilişkilerinin incelenmesi amaçlanmıştır.

\section{MATERYAL ve METOT}

Araştırmanın deseni: Bu araştırma gönüllü katılımciların bazı performans testlerini ve ölçümlerini içeren uygulama türünde, tanımlayıcı modelde bir çalışmadır. Araştırmada katılımcıların vücut kompozisyonları, aero- bik ve anaerobik özellikleri ve esneklik özellikleri belirlenmiştir.

Araştırma grubu: Çalı̧smaya Ahi Evran Üniversitesi Beden Eğitimi ve Spor Yüksekokulunda son sınıfta (4.sınıf) öğrenim gören 18 kadın, 13 erkek olmak üzere toplam 31 öğrenci gönüllü olarak katılmıştır. Katılımc1ların yaş ortalamaları $\dot{x}=21$ 'dir. Katılımcılar çalışmaya alınmadan önce sözel olarak bilgilendirildikten sonra, yazılı olarak bilgilendirilmiş onamları alınmıştır.

Vücut kompozisyonunu belirlenmesi: Bu çalışmada vücut segmentlerine göre vücut kompozisyonunu belirlemek amaciyla TANITA-BC601 INNERSCAN vücut analiz tartısı aracılı̆̆ıyla bioelektrik impedans analiz yöntemi kullanılmıştır. Vücut segmentleri; sağ kol, sağ kol sol kol, sağ bacak, sol bacak olarak ele alınmıştır. Böylelikle sağ kol kas, sağ kol yağ, sol kol kas, sol kol yağ, sağ bacak kas, sağ bacak yağ, sol bacak kas, sol bacak kas, total vücut kas kütlesi, total vücut yağ kütlesi ve vücut kitle indeksi (VKİ) analiz edilmiştir.

Aerobik performans testi: Aerobik performansı ölçmek için Cooper (koş-yürü) testi uygulanmıştır. Cooper testi Dr. Kenneth Cooper'n aerobik performansı belirlemek için geliştirdiği bu test 12 dakikalık koşu ya da yürüyüş şeklinde uygulanan bir protokoldür. 12 dakika koş-yürü testi (Cooper) Max 
International Refereed Academic Journal of Sports, Health and Medical Sciences October - November - December Issue: 29 Fall Winter Semester Year: 2018

Uluslararası Hakemli Akademik Spor Sağlık ve Tıp Bilimleri Dergisi Ekim - Kasım - Aralık Sayı: 29 Güz Kış Dönemi Yıl: 2018 ID:410 K:318

ISSN Print: 2146-8508 Online 2147-1711

(ISO 18001-OH-0090-13001706 / ISO 14001-EM-0090-13001706 / ISO 9001-QM-0090-13001706 / ISO 10002-CM-0090-13001706) (TRADEMARK)

VO2 değerleri Balke formülü kullanılarak belirlenmiştir (Tamer, 2000).

$\mathrm{VO} 2 \mathrm{ml} / \mathrm{kg}$-dakika $=33.3+(\mathrm{x}-150) .0 .178$ $\mathrm{ml} / \mathrm{kg}-\mathrm{dk}$

\section{Anaerobik Performans Belirleme Testleri}

30 metre sprint testi: Kat1lımc1ların 30 metre sprint süratinin belirlenmesinde Smart Speed markalı fotosel cihazı kullanılmıştır. Bu ölçüm spor salonunda 30 metrelik mesafe belirlenerek yapılmıştır. Katılımcılar başlangıç fotoselinin bir metre gerisinden hazır oldukları anda teste başlamıştır. Teste başlamadan önce 15 dakikalık jogging ve stretching içeren bir 1sınma yapılmıştır. Test her katılımcıya 5 dakikalık aralıklarla 2 kere yaptırılmış ve en iyi dereceleri değerlendirmeye alınmıştır. Bu testin güvenilirlik katsayısı $0,74-0,97$ olarak bildirilmiştir (Özkara, 2002).

Dikey sıçrama testi: $\mathrm{Bu}$ ölçüm düz bir duvarda yapılmaktadır. Kişi ayakları yerden kalkamayacak şekilde uzanabildiği kadar duvara uzanır. Uzandığı bölgeden sıçrayarak dokunabildiği nokta arasındaki mesafe metre cinsinden ölçülür. Daha sonra sporcuların vücut ağırlıklarından da yararlanılarak aşağıdaki formül ile anaerobik güç hesaplaması yapılmıştır (Salles ve diğ., 2012; Cicoğlu ve diğ., 1996):
$P=\sqrt{ } 4.9 X \mathrm{~W} X \sqrt{\mathrm{D}}$

$\mathrm{P}=$ Anaerobik Güç

W =Vücut Ağırlı̆̆ı (kg)

$\mathrm{D}=$ Siçrama Mesafesi (m)

Esneklik testi: Katılımcıların esnekliğini belirleyebilmek için kalça fleksiyonu için oturuzan testi literatürde belirtildiği gibi kullanılmıştır (Mathews, 1978, Dikki, 1992, Tamer, 2000, Heyward, 2006). Duvara dayalı şekilde duran otur-uzan sehpasının alt kısmına ayakkabısız olarak ayaklar dayanmıştır. Bu pozisyonda, katılımcılar dizleri bükmeden ileriye doğru uzanarak sehpanın üzerindeki cetveli maksimum performansla iterek en az 5 saniye beklemişlerdir. Esneklik sehpası üzerindeki cetvelde uzanılan en uzun mesafe santimetre cinsinden esneklik değeri olarak kaydedilmiştir. 2 kere deneme alındıktan sonra en iyi sonuç değerlendirmeye alınmıştır.

\section{İstatistiksel Analiz}

$\mathrm{Bu}$ araştırmadan elde edilen veriler Windows için SPSS 22.0 paket programı kullanılarak tanımlayıcı istatistikler ve Spearman Korelasyon analizi yapılmıştır. 
SSTB

www.sstbdergisi.com

International Refereed Academic Journal of Sports, Health and Medical Sciences

October - November - December Issue: 29 Fall Winter Semester Year: 2018

Uluslararası Hakemli Akademik Spor Sağlık ve Tıp Bilimleri Dergisi

Ekim - Kasım - Aralık Sayı: 29 Güz Kış Dönemi Yıl: 2018

ID:410 K:318

ISSN Print: 2146-8508 Online 2147-1711

(ISO 18001-OH-0090-13001706 / ISO 14001-EM-0090-13001706 / ISO 9001-QM-0090-13001706 / ISO 10002-CM-0090-13001706) (TRADEMARK)

(2015/04315- 2015-GE-18972)

\section{BULGULAR}

Tablo 1. Araştırmaya Katılan Üniversiteli Erkek ve Kadın Öğrencilerin Tanımlayıcı İstatistikleri

\begin{tabular}{|c|c|c|}
\hline Değişkenler & $\begin{array}{l}\text { Erkek } \\
\mathrm{N}=13\end{array}$ & $\begin{array}{l}\text { Kadın } \\
\mathrm{N}=18\end{array}$ \\
\hline & $\mathrm{x} \pm \mathrm{sd}$ & $\mathrm{x} \pm \mathrm{sd}$ \\
\hline Cooper & $41,12 \pm 8,11$ & $28,36 \pm 6,42$ \\
\hline Esneklik & $32,07 \pm 6,06$ & $33,17 \pm 8,47$ \\
\hline Dikey Sıçrama & $37,38 \pm 7,91$ & $27,50 \pm 4,15$ \\
\hline 30m Sürat & $4,17 \pm, 20$ & $5,27 \pm 0,37$ \\
\hline Vücut Yağ \% & $16,60 \pm 5,15$ & $23,75 \pm 5,70$ \\
\hline Kas Kütlesi & $62,18 \pm 8,11$ & $42,05 \pm 3,89$ \\
\hline VKİ & $25,62 \pm 3,38$ & $21,18 \pm 3,01$ \\
\hline Sağ Kol Kas & $3,88 \pm, 81$ & $2,04 \pm 0,28$ \\
\hline Sağ Kol Yağ & $13,46 \pm 5,64$ & $23,02 \pm 7,61$ \\
\hline Sol Kol Kas & $3,84 \pm, 82$ & $1,98 \pm 0,28$ \\
\hline Sol Kol Yağ & $14,58 \pm 5,81$ & $23,83 \pm 7,44$ \\
\hline Sağ Bacak Kas & $10,91 \pm 1,13$ & $7,13 \pm 0,63$ \\
\hline Sağ Bacak Yağ & $14,40 \pm 4,46$ & $29,27 \pm 4,72$ \\
\hline Sol Bacak Kas & $10,75 \pm 1,18$ & $7,01 \pm 0,70$ \\
\hline Sol Bacak Yağ & $14,78 \pm 3,76$ & $29,46 \pm 4,48$ \\
\hline
\end{tabular}

Tablo 1 incelendiğinde kadın ve erkek öğrencilerin Cooper testi, esneklik testi, dikey sıçrama testi ve vücut kompozisyonlarını içeren vücut yağ yüzdesi, kas kütlesi, vücut kitle indeksi ve vücut segmentlerine farklı bölgelerdeki göre yă̆ ve kas oranları görülmektedir. Kadınların aerobik (Cooper) ve anaerobik (30 m sürat, dikey sıçrama) test sonuçlarının erkeklerden daha düşük olduğu, esneklik test sonuçlarına bakıldığında ise kadınların esneklik değerimin erkeklerden biraz daha yüksek olduğu görülmüştür. Vücut yağ yüzdesi kadınlarda daha yüksek iken kas kütlesinin erkeklerde yüksek olduğu görülmektedir. Vücut segmentlerine göre yağ oranlarına bakıldığında ise yine kadınlarda daha yüksek olduğu, kas oranları sonuçlarında ise yine erkeklerde daha yüksek olduğu görülmektedir. 
SSTB

www.sstbdergisi.com

International Refereed Academic Journal of Sports, Health and Medical Sciences October - November - December Issue: 29 Fall Winter Semester Year: 2018

Uluslararası Hakemli Akademik Spor Sağlık ve Tıp Bilimleri Dergisi Ekim - Kasım - Aralık Sayı: 29 Güz Kış Dönemi Yıl: 2018 ID:410 K:318

ISSN Print: 2146-8508 Online 2147-1711

(ISO 18001-OH-0090-13001706 / ISO 14001-EM-0090-13001706 / ISO 9001-QM-0090-13001706 / ISO 10002-CM-0090-13001706) (TRADEMARK)

(2015/04315- 2015-GE-18972)

Tablo 2. Araştırmaya Katılan Üniversiteli Erkek Öğrencilerin Bazı Fiziksel ve Fizyolojik Parametreleri Arasındaki İlişki

\begin{tabular}{|c|c|c|c|c|c|c|c|c|c|c|c|c|c|c|c|}
\hline $\begin{array}{l}\mathrm{N}=13 \\
\text { Erkek }\end{array}$ & & Cooper & $\begin{array}{l}\text { Es- } \\
\text { neklik }\end{array}$ & $\begin{array}{l}\text { Dikey } \\
\text { Siçra- } \\
\text { ma }\end{array}$ & Sürat & $\begin{array}{l}\text { Vücut } \\
\text { Yağ } \\
\%\end{array}$ & $\begin{array}{l}\text { Kas } \\
\text { Kütlesi }\end{array}$ & VKİ & $\begin{array}{l}\text { Sağ } \\
\text { Kol } \\
\text { Kas }\end{array}$ & $\begin{array}{l}\text { Sağ } \\
\text { Kol } \\
\text { Yağ }\end{array}$ & $\begin{array}{l}\text { Sol } \\
\text { Kol } \\
\text { Kas }\end{array}$ & $\begin{array}{l}\text { Sol } \\
\text { Kol } \\
\text { Yağ }\end{array}$ & $\begin{array}{l}\text { Sağ } \\
\text { Bacak } \\
\text { Kas }\end{array}$ & $\begin{array}{l}\text { Sağ } \\
\text { Bacak } \\
\text { Yağ }\end{array}$ & $\begin{array}{l}\text { Sol } \\
\text { Ba- } \\
\text { cak } \\
\text { Kas }\end{array}$ \\
\hline \multirow[t]{2}{*}{ Esneklik } & $\mathrm{r}$ &,- 234 & & & & & & & & & & & & & \\
\hline & $\mathrm{p}$ &, 442 & & & & & & & & & & & & & \\
\hline \multirow{2}{*}{$\begin{array}{l}\text { Dikey } \\
\text { siçrama }\end{array}$} & $\mathrm{r}$ &, 512 &, 058 & & & & & & & & & & & & \\
\hline & $\mathrm{p}$ &, 074 &, 850 & & & & & & & & & & & & \\
\hline \multirow[t]{2}{*}{ Sürat } & $\mathrm{r}$ &,$- 840^{* * *}$ &, 237 &,- 524 & & & & & & & & & & & \\
\hline & $\mathrm{p}$ &, 000 & ,437 & ,066 & & & & & & & & & & & \\
\hline \multirow{2}{*}{$\begin{array}{l}\text { Vücut } \\
\text { yağ } \\
\text { yüzdesi }\end{array}$} & $\mathrm{r}$ &,- 206 &,- 079 &,- 454 & ,297 & & & & & & & & & & \\
\hline & $\mathrm{p}$ &, 501 & ,798 &, 119 & ,325 & & & & & & & & & & \\
\hline \multirow{2}{*}{$\begin{array}{l}\text { Kas } \\
\text { kütlesi }\end{array}$} & $\mathrm{r}$ &,- 388 &, 157 &,$- 631^{*}$ &, $642^{*}$ & ,036 & & & & & & & & & \\
\hline & $\mathrm{p}$ & ,190 & ,608 &, 021 &, 018 & ,908 & & & & & & & & & \\
\hline \multirow[t]{2}{*}{ VKİ } & $\mathrm{r}$ &,- 335 &, 242 &,$- 609^{*}$ &, 548 &, $635^{*}$ &, $619^{*}$ & & & & & & & & \\
\hline & $\mathrm{p}$ &, 263 & ,426 &, 027 &, 053 & ,020 &, 024 & & & & & & & & \\
\hline \multirow{2}{*}{$\begin{array}{l}\text { Sağ kol } \\
\text { kas }\end{array}$} & $\mathrm{r}$ &,- 452 &, 391 &,- 504 &, $674^{*}$ &,- 110 &, $924^{* * * *}$ &, $606^{*}$ & & & & & & & \\
\hline & $\mathrm{p}$ &, 121 &, 187 &, 079 &, 012 &, 719 &, 000 &, 028 & & & & & & & \\
\hline \multirow{2}{*}{$\begin{array}{l}\text { Sağ kol } \\
\text { yağg }\end{array}$} & $\mathrm{r}$ &,- 077 &,- 030 &,- 119 &, 124 &, $834^{* * * *}$ &,- 258 & ,418 &,- 342 & & & & & & \\
\hline & $\mathrm{p}$ & ,802 & ,922 & ,699 &, 687 &, 000 & ,394 &, 155 &, 253 & & & & & & \\
\hline \multirow{2}{*}{$\begin{array}{l}\text { Sol kol } \\
\text { kas }\end{array}$} & $\mathrm{r}$ &,- 426 & ,192 &,- 530 &, $673^{*}$ &,- 099 &, $955^{* * *}$ &, $584^{*}$ &, $968^{* * *}$ &,- 358 & & & & & \\
\hline & $\mathrm{p}$ & ,146 &, 530 &, 062 &, 012 &, 747 &, 000 & ,036 &, 000 &, 230 & & & & & \\
\hline \multirow{2}{*}{$\begin{array}{l}\text { Sol kol } \\
\text { yağ }\end{array}$} & $\mathrm{r}$ &,- 091 &, 074 &,- 133 &, 118 &, $869^{* * * *}$ &,- 264 &, 421 &,- 334 &, $978^{* * * *}$ &,- 377 & & & & \\
\hline & $\mathrm{p}$ & ,768 & ,809 &, 665 &, 700 &, 000 & ,384 & ,152 &, 265 &, 000 & ,204 & & & & \\
\hline \multirow{2}{*}{$\begin{array}{l}\text { Sağ } \\
\text { bacak } \\
\text { kas }\end{array}$} & $\mathrm{r}$ &,- 270 &, 110 &,$- 593^{*}$ &, $563^{*}$ &, 251 &, $930^{* * *}$ &, $708^{* * *}$ &, $798^{* *}$ & ,008 &, $821^{* *}$ &, 008 & & & \\
\hline & $\mathrm{p}$ &, 372 &, 719 &, 033 & ,045 & ,409 &, 000 &, 007 &, 001 & ,979 &, 001 & ,979 & & & \\
\hline \multirow{2}{*}{$\begin{array}{l}\text { Sağ } \\
\text { bacak } \\
\text { yağ }\end{array}$} & $\mathrm{r}$ &,- 404 & ,094 &,$- 587^{*}$ &, 528 &, $639^{*}$ &, 451 &, $876^{* * * *}$ & ,463 & ,358 & ,468 &, 355 &, 449 & & \\
\hline & $\mathrm{p}$ &, 171 &, 760 &, 035 &, 063 & ,019 &, 122 &, 000 &, 111 & ,230 & ,107 &, 234 &, 124 & & \\
\hline \multirow{2}{*}{$\begin{array}{l}\text { Sol ba- } \\
\text { cak kas }\end{array}$} & $\mathrm{r}$ &,- 360 & ,086 &,$- 718^{* *}$ &, $615^{*}$ &, 263 &, $964^{* * *}$ &, $717^{* *}$ &, $835^{* * *}$ &,- 061 &, $872^{* * * *}$ &,- 052 &, $964^{* * *}$ &, 541 & \\
\hline & $\mathrm{p}$ &, 226 &, 781 & ,006 & ,025 & ,384 &, 000 & ,006 &, 000 &, 844 &, 000 &, 865 &, 000 &, 056 & \\
\hline \multirow{2}{*}{$\begin{array}{l}\text { Sol } \\
\text { bacak } \\
\text { yağ }\end{array}$} & $\mathrm{r}$ &,- 265 & ,149 &,- 457 &, 394 &, $742^{* *}$ &, 341 &, $895^{* * * *}$ &, 343 &, 512 &, 325 &, 531 & ,435 &, $953^{* * * *}$ & ,474 \\
\hline & $\mathrm{p}$ & ,382 &, 627 &, 116 &, 182 & ,004 &, 254 &, 000 &, 252 & ,074 &, 278 &, 062 & ,137 &, 000 & , 101 \\
\hline
\end{tabular}


International Refereed Academic Journal of Sports, Health and Medical Sciences

October - November - December Issue: 29 Fall Winter Semester Year: 2018

Uluslararası Hakemli Akademik Spor Sağlık ve Tıp Bilimleri Dergisi

Ekim - Kasım - Aralık Sayı: 29 Güz Kış Dönemi Yıl: 2018 ID:410 K:318

ISSN Print: 2146-8508 Online 2147-1711

(ISO 18001-OH-0090-13001706 / ISO 14001-EM-0090-13001706 / ISO 9001-QM-0090-13001706 / ISO 10002-CM-0090-13001706) (TRADEMARK)

$* \mathrm{p}<0.05 \quad * * \mathrm{p}<0.01 \quad * * * \mathrm{p}<0.001$

r: Spearman'1n yorumu

(r) korelasyon katsayısı; 0.00-0.25 çok zayıf, 0.26-0.49 zayıf, $0.50-0.69$ orta, $0.70-0.89$ yüksek, 0.90-1.00 çok yüksek

Tablo 2'de araştırmaya katılan erkek öğrencilerin bazı fiziksel ve fizyolojik parametreleri arasındaki ilişkiye yer verilmiştir (korelasyon-spearman). Yapılan analiz sonucunda;

Cooper ve sürat arasında ( $\mathrm{r}=-, 840, \mathrm{p}<0.001)$, negatif yönlü yüksek düzeyde anlamlı bir ilişki,

Dikey sıçrama ve kas kütlesi arasında ( $\mathrm{r}=-$ ,631, p<0.05), negatif yönlü orta düzeyde anlamlı bir ilişki,

Dikey sıçrama ve VKİ arasında (r=-,609, $\mathrm{p}<0.05$ ), negatif yönlü orta düzeyde anlamlı bir ilişki,

Dikey sıçrama ve sağ bacak kas arasında ( $\mathrm{r}=$ ,593, $\mathrm{p}<0.05)$, negatif yönlü orta düzeyde anlamlı bir ilişki,

Dikey sıçrama ve sağ bacak yağ arasında ( $\mathrm{r}=$ ,587, $\mathrm{p}<0.05)$, negatif yönlü orta düzeyde anlamlı bir ilişki,

Dikey sıçrama ve sol bacak kas arasında ( $\mathrm{r}=$ ,718, p<0.01), negatif yönlü yüksek düzeyde anlamlı bir ilişki,
Sürat ve kas kütlesi arasında $(r=, 642, p<0.05)$, pozitif yönlü orta düzeyde anlamlı bir ilişki,

Sürat ve sağ kol kas arasında $(r=, 674, \mathrm{p}<0.05)$, pozitif yönlü orta düzeyde anlamlı bir ilişki,

Sürat ve sol kol kas arasında $(r=, 673, p<0.05)$, pozitif yönlü orta düzeyde anlamlı bir ilişki,

Sürat ve sağ bacak kas arasında $(\mathrm{r}=, 563$, $\mathrm{p}<0.05$ ), pozitif yönlü orta düzeyde anlamlı bir ilişki,

Sürat ve sol bacak kas arasında $(\mathrm{r}=, 615$, $\mathrm{p}<0.05$ ), pozitif orta düzeyde anlamlı bir ilişki,

Vücut yă̆ \% ve VKİ arasında ( $\mathrm{r}=, 635$, $\mathrm{p}<0.05$ ), pozitif yönlü orta düzeyde anlamlı bir ilişki,

Vücut yağ \% ve sağ kol yağ arasında ( $\mathrm{r}=, 834$, $\mathrm{p}<0.001$ ), pozitif yönlü yüksek düzeyde anlamlı bir ilişki,

Vücut yağ \% ve sol kol yağ arasında ( $\mathrm{r}=, 869$, $\mathrm{p}<0.001$ ), pozitif yönlü yüksek düzeyde anlamlı bir ilişki,

Vücut yağ \% ve sağ bacak yağ arasında $(\mathrm{r}=, 639, \mathrm{p}<0.05)$, pozitif yönlü orta düzeyde anlamlı bir ilişki,

Vücut yağ \% ve sol bacak yağ arasında $(\mathrm{r}=, 742, \mathrm{p}<0.01)$, pozitif yüksek düzeyde anlamlı bir ilişki,

Kas kütlesi ve VKİ arasında ( $\mathrm{r}=, 619, \mathrm{p}<0.05)$, pozitif yönlü orta düzeyde anlamlı bir ilişki, 
International Refereed Academic Journal of Sports, Health and Medical Sciences October - November - December Issue: 29 Fall Winter Semester Year: 2018

Uluslararası Hakemli Akademik Spor Sağlık ve Tıp Bilimleri Dergisi Ekim - Kasım - Aralık Sayı: 29 Güz Kış Dönemi Yıl: 2018 ID:410 K:318

ISSN Print: 2146-8508 Online 2147-1711

(ISO 18001-OH-0090-13001706 / ISO 14001-EM-0090-13001706 / ISO 9001-QM-0090-13001706 / ISO 10002-CM-0090-13001706) (TRADEMARK)

Kas kütlesi ve sağ kol kas arasında (r=,924, $\mathrm{p}<0.001$ ), pozitif yönlü çok yüksek düzeyde anlamlı bir ilişki,

Kas kütlesi ve sol kol kas arasında ( $\mathrm{r}=, 955$, $\mathrm{p}<0.001$ ), pozitif yönlü çok yüksek düzeyde anlamlı bir ilişki,

Kas kütlesi ve sağ bacak kas arasında ( $\mathrm{r}=, 930$, $\mathrm{p}<0.001$ ), pozitif çok yüksek düzeyde anlamlı bir ilişki,

Kas kütlesi ve sol bacak kas arasında (r=,964, $\mathrm{p}<0.001$ ), pozitif çok yüksek düzeyde anlam11 bir ilişki,

VKİ ve sağ kol kas arasında $(r=, 606, p<0.05)$, pozitif yönlü orta düzeyde anlamlı bir ilişki,

VKİ ve sol kol kas arasında $(r=, 584, p<0.05)$, pozitif yönlü orta düzeyde anlamlı bir ilişki,

VKİ ve sağ bacak kas arasında $(r=, 708$, $\mathrm{p}<0.01$ ), pozitif çok yüksek düzeyde anlamlı bir ilişki,

VKİ ve sağ bacak yağ arasında $(r=, 876$, $\mathrm{p}<0.001$ ), pozitif yüksek düzeyde anlamlı bir ilişki,

VKİ ve sol bacak kas arasinda ( $\mathrm{r}=, 717$, $\mathrm{p}<0.01$ ), pozitif yüksek düzeyde anlamlı bir ilişki,
VKİ ve sol bacak yağ arasında $(r=, 895$, $\mathrm{p}<0.001$ ), pozitif yüksek düzeyde anlamlı bir ilişki,

Sağ kol kas ve sol kol kas arasında ( $\mathrm{r}=, 968$, $\mathrm{p}<0.001$ ), pozitif çok yüksek düzeyde anlam11 bir ilişki,

Sağ kol kas ve sağ bacak kas arasında (r=,798, $\mathrm{p}<0.01$ ), pozitif yüksek düzeyde anlamlı bir ilişki,

Sağ kol kas ve sol bacak kas arasında $(r=, 835$, $\mathrm{p}<0.001$ ), pozitif yüksek düzeyde anlamlı bir ilişki,

Sağ kol yağ ve sol kol yağ arasında ( $\mathrm{r}=, 978$, $\mathrm{p}<0.001$ ), pozitif çok yüksek düzeyde anlam11 bir ilişki,

Sol kol kas ve sağ bacak kas arasında $(\mathrm{r}=, 821$, $\mathrm{p}<0.01$ ), pozitif yüksek düzeyde anlamlı bir ilişki,

Sol kol kas ve sol bacak kas arasinda $(\mathrm{r}=, 872$, $\mathrm{p}<0.001$ ), pozitif yüksek düzeyde anlamlı bir ilişki,

Sağ bacak kas ve sol bacak kas arasında ( $r=, 964, p<0.001)$, pozitif çok yüksek düzeyde anlamlı bir ilişki,

Sağ bacak yağ ve sol bacak yağ arasında $(\mathrm{r}=, 953, \mathrm{p}<0.001)$, pozitif çok yüksek düzeyde anlamlı bir ilişki olduğu görülmüştür. 


\section{(2)

SSTB

www.sstbdergisi.com

International Refereed Academic Journal of Sports, Health and Medical Sciences October - November - December Issue: 29 Fall Winter Semester Year: 2018

Uluslararası Hakemli Akademik Spor Sağlık ve Tıp Bilimleri Dergisi

Ekim - Kasım - Aralık Sayı: 29 Güz Kıș Dönemi Yıl: 2018 ID:410 K:318

ISSN Print: 2146-8508 Online 2147-1711

(ISO 18001-OH-0090-13001706 / ISO 14001-EM-0090-13001706 / ISO 9001-QM-0090-13001706 / ISO 10002-CM-0090-13001706) (TRADEMARK)

(2015/04315- 2015-GE-18972)

Tablo 3. Araştırmaya Katılan Üniversiteli Kadın Öğrencilerin Bazı Fiziksel ve Fizyolojik Parametreleri Arasındaki İlişki

\begin{tabular}{|c|c|c|c|c|c|c|c|c|c|c|c|c|c|c|c|}
\hline $\begin{array}{l}\mathrm{N}=18 \\
\text { Kadın }\end{array}$ & & $\begin{array}{l}\text { Coo- } \\
\text { per }\end{array}$ & $\begin{array}{l}\text { Esnek- } \\
\text { lik }\end{array}$ & $\begin{array}{l}\text { Dikey } \\
\text { Siçra- } \\
\text { ma }\end{array}$ & Sürat & $\begin{array}{l}\text { Vücut } \\
\text { Yağ } \\
\%\end{array}$ & $\begin{array}{l}\text { Kas } \\
\text { Kütlesi }\end{array}$ & VKİ & $\begin{array}{l}\text { Sağ } \\
\text { Kol } \\
\text { Kas }\end{array}$ & $\begin{array}{l}\text { Sağ } \\
\text { Kol } \\
\text { Yağ }\end{array}$ & $\begin{array}{l}\text { Sol } \\
\text { Kol } \\
\text { Kas }\end{array}$ & $\begin{array}{l}\text { Sol } \\
\text { Kol } \\
\text { Yağ }\end{array}$ & $\begin{array}{l}\text { Sağ } \\
\text { Bacak } \\
\text { Kas }\end{array}$ & $\begin{array}{l}\text { Sağ } \\
\text { Bacak } \\
\text { Yağ }\end{array}$ & $\begin{array}{l}\text { Sol } \\
\text { Bacak } \\
\text { Kas }\end{array}$ \\
\hline \multirow[t]{2}{*}{ Esneklik } & $\mathrm{r}$ & ,002 & & & & & & & & & & & & & \\
\hline & $\mathrm{p}$ & 993 & & & & & & & & & & & & & \\
\hline \multirow{2}{*}{$\begin{array}{l}\text { Dikey sıçra- } \\
\text { ma }\end{array}$} & $\mathrm{r}$ &,- 029 &, 085 & & & & & & & & & & & & \\
\hline & $\mathrm{p}$ & ,908 &, 737 & & & & & & & & & & & & \\
\hline \multirow[t]{2}{*}{ Sürat } & $\mathrm{r}$ &,- 133 &, 327 &,- 416 & & & & & & & & & & & \\
\hline & $\mathrm{p}$ & ,600 & ,186 &, 086 & & & & & & & & & & & \\
\hline \multirow{2}{*}{$\begin{array}{l}\text { Vücut yağ } \\
\text { yüzdesi }\end{array}$} & $\mathrm{r}$ &,- 314 & ,098 &, 068 & ,312 & & & & & & & & & & \\
\hline & $\mathrm{p}$ & ,205 & ,698 & ,787 & ,208 & & & & & & & & & & \\
\hline \multirow[t]{2}{*}{ Kas kütlesi } & $\mathrm{r}$ &,- 038 & ,012 &,- 065 &,- 251 & ,312 & & & & & & & & & \\
\hline & $\mathrm{p}$ &, 880 & ,963 & ,799 & ,315 & ,208 & & & & & & & & & \\
\hline \multirow[t]{2}{*}{ VKİ } & $\mathrm{r}$ &,- 140 & ,066 & ,026 &, 152 & ,908* &, $476^{*}$ & & & & & & & & \\
\hline & $\mathrm{p}$ &, 580 & ,795 & ,918 &, 548 &, 000 & ,046 & & & & & & & & \\
\hline \multirow[t]{2}{*}{ Sağ kol kas } & $\mathrm{r}$ &,- 106 &,- 061 &,- 210 &,- 186 & ,349 &, $950^{* * * *}$ &, $507^{*}$ & & & & & & & \\
\hline & $\mathrm{p}$ &, 676 &, 810 & ,404 & ,459 &, 156 &, 000 &, 032 & & & & & & & \\
\hline \multirow{2}{*}{$\begin{array}{l}\text { Sağ Kol } \\
\text { Yağ }\end{array}$} & $\mathrm{r}$ &,- 207 &, 251 & ,301 & ,299 &, $804^{*}$ &, 073 &, $738^{* * * *}$ &, 028 & & & & & & \\
\hline & $\mathrm{p}$ & ,410 & ,314 & ,224 &, 229 &, 000 &, 773 &, 000 & ,912 & & & & & & \\
\hline \multirow[t]{2}{*}{ Sol kol kas } & $\mathrm{r}$ &,- 113 &,- 062 &,- 160 &,- 186 & ,431 &, $960^{* * *}$ &, $598^{* *}$ &, $968^{* * * *}$ &, 150 & & & & & \\
\hline & $\mathrm{p}$ &, 655 & ,807 &, 527 & ,459 &, 074 &, 000 & ,009 &, 000 &, 554 & & & & & \\
\hline \multirow[t]{2}{*}{ Sol kol yağ } & $\mathrm{r}$ &,- 325 &, 219 &, 345 &, 314 &, $761^{*}$ &,- 072 &, $623^{* *}$ &,- 066 &, $904^{* * *}$ &, 005 & & & & \\
\hline & $\mathrm{p}$ &, 188 & ,382 &, 160 & ,204 &, 000 &, 776 &, 006 & ,796 &, 000 & ,984 & & & & \\
\hline \multirow{2}{*}{$\begin{array}{l}\text { Sağ bacak } \\
\text { kas }\end{array}$} & $\mathrm{r}$ &,- 052 &,- 085 &,- 011 &,- 171 &, $481^{*}$ &, $933^{* * *}$ &, $617^{* *}$ &, $946^{* * * *}$ &, 215 &, $928^{* * *}$ &, 135 & & & \\
\hline & $\mathrm{p}$ & ,836 &, 738 & ,966 & ,497 &, 043 &, 000 & ,006 &, 000 & ,392 &, 000 &, 592 & & & \\
\hline \multirow{2}{*}{$\begin{array}{l}\text { Sağ bacak } \\
\text { yağ }\end{array}$} & $\mathrm{r}$ &,- 205 &, 088 &,- 096 & ,398 &, $868^{*}$ & ,205 &, $830^{* * * *}$ &, 189 &, $678^{* *}$ &, 317 &, $578^{*}$ & ,298 & & \\
\hline & $\mathrm{p}$ & ,414 &, 728 &, 705 &, 102 &, 000 &, 414 &, 000 &, 453 & ,002 & ,200 &, 012 &, 229 & & \\
\hline \multirow{2}{*}{$\begin{array}{l}\text { Sol bacak } \\
\text { kas }\end{array}$} & $\mathrm{r}$ &, 035 &,- 144 &,- 041 &,- 251 &, 424 &, $927^{* * * *}$ &, $584^{*}$ &, $953^{* * * *}$ &, 127 &, $928^{* * *}$ &, 034 &, $967^{* * * *}$ &, 236 & \\
\hline & $\mathrm{p}$ &, 891 &, 570 &, 871 &, 315 &, 080 &, 000 &, 011 &, 000 &, 615 &, 000 &, 893 &, 000 & ,346 & \\
\hline \multirow{2}{*}{$\begin{array}{l}\text { Sol bacak } \\
\text { yağ }\end{array}$} & $\mathrm{r}$ &,- 320 &, 066 &,- 075 &, 430 &, $861^{* * * *}$ &, 077 &, $774^{* * * *}$ &, 078 & ,699** &, 213 &, $639^{* *}$ &, 187 &, $977^{* * *}$ &, 106 \\
\hline & $\mathrm{p}$ &, 195 & ,794 & ,768 & ,075 &, 000 &, 760 &, 000 & ,760 & ,001 & ,395 & ,004 & ,458 &, 000 &, 677 \\
\hline
\end{tabular}


International Refereed Academic Journal of Sports, Health and Medical Sciences October - November - December Issue: 29 Fall Winter Semester Year: 2018

Uluslararası Hakemli Akademik Spor Sağlık ve Tıp Bilimleri Dergisi Ekim - Kasım - Aralık Sayı: 29 Güz Kış Dönemi Yıl: 2018 ID:410 K:318

ISSN Print: 2146-8508 Online 2147-1711

(ISO 18001-OH-0090-13001706 / ISO 14001-EM-0090-13001706 / ISO 9001-QM-0090-13001706 / ISO 10002-CM-0090-13001706) (TRADEMARK)

$* \mathrm{p}<0.05 \quad * * \mathrm{p}<0.01 \quad * * * \mathrm{p}<0.001$

r: Spearman'1n yorumu

(r) korelasyon katsayısı; 0.00-0.25 çok zayıf, 0.26-0.49 zayıf, 0.50-0.69 orta, 0.70-0.89 yüksek, 0.90-1.00 çok yüksek

Tablo 3'te araştırmaya katılan kadın öğrencilerin bazı fiziksel ve fizyolojik parametrelerini arasındaki ilişkiye yer verilmiştir (korelasyon-spearman). Yapılan analiz sonucunda;

Vücut yă̆ \% ve VKİ arasında (r=,908, $\mathrm{p}<0.001$ ), pozitif yönlü çok yüksek düzeyde anlamlı bir ilişski,

Vücut yağ \% ve sağ kol yăg arasında $(\mathrm{r}=, 804$, $\mathrm{p}<0.001$ ), pozitif yönlü yüksek düzeyde anlamlı bir ilişki,

Vücut yă̆ \% ve sol kol yağ arasında (r=,761, $\mathrm{p}<0.001$ ), pozitif yönlü yüksek düzeyde anlamlı bir ilişki,

Vücut yağ \% ve sağ bacak kas arasında $(\mathrm{r}=, 481, \mathrm{p}<0.05)$, pozitif yönlü zayıf düzeyde anlamlı bir ilişki,

Vücut yağ \% ve sağ bacak yağ arasında $(\mathrm{r}=, 868, \mathrm{p}<0.001)$, pozitif yönlü yüksek düzeyde anlamlı bir ilişki,

Vücut yağ \% ve sol bacak yağ arasında $(\mathrm{r}=, 861, \mathrm{p}<0.001)$, pozitif yüksek düzeyde anlamlı bir ilişki,
Kas kütlesi ve VKİ arasında ( $\mathrm{r}=, 476, \mathrm{p}<0.05)$, pozitif yönlü zayıf düzeyde anlamlı bir ilişki,

Kas kütlesi ve sağ kol kas arasında (r=,950, $\mathrm{p}<0.001$ ), pozitif yönlü çok yüksek düzeyde anlamlı bir ilişki,

Kas kütlesi ve sol kol kas arasında ( $\mathrm{r}=, 960$, $\mathrm{p}<0.001$ ), pozitif yönlü çok yüksek düzeyde anlamlı bir ilişki,

Kas kütlesi ve sağ bacak kas arasında $(\mathrm{r}=, 933$, $\mathrm{p}<0.001$ ), pozitif çok yüksek düzeyde anlam11 bir ilişki,

Kas kütlesi ve sol bacak kas arasında ( $\mathrm{r}=, 927$, $\mathrm{p}<0.001$ ), pozitif çok yüksek düzeyde anlam11 bir ilişki,

VKİ ve sağ kol kas arasında $(r=, 507, p<0.05)$, pozitif yönlü orta düzeyde anlamlı bir ilişki,

VKİ ve sağ kol yağ arasında (r=,738, $\mathrm{p}<0.001$ ), pozitif yönlü yüksek düzeyde anlamlı bir ilişki,

VKİ ve sol kol kas arasında $(r=, 598, p<0.01)$, pozitif yönlü orta düzeyde anlamlı bir ilişki,

VKİ ve sol kol yağ arasında $(r=, 623, p<0.01)$, pozitif yönlü orta düzeyde anlamlı bir ilişki,

VKİ ve sağ bacak kas arasında ( $r=, 617$, $\mathrm{p}<0.01$ ), pozitif orta düzeyde anlamlı bir ilişki,

VKİ ve sağ bacak yağ arasında $(\mathrm{r}=, 830$, $\mathrm{p}<0.001$ ), pozitif yüksek düzeyde anlamlı bir ilişki, 
International Refereed Academic Journal of Sports, Health and Medical Sciences

October - November - December Issue: 29 Fall Winter Semester Year: 2018

Uluslararası Hakemli Akademik Spor Sağlık ve Tıp Bilimleri Dergisi

Ekim - Kasım - Aralık Sayı: 29 Güz Kış Dönemi Yıl: 2018 ID:410 K:318

ISSN Print: 2146-8508 Online 2147-1711

(ISO 18001-OH-0090-13001706 / ISO 14001-EM-0090-13001706 / ISO 9001-QM-0090-13001706 / ISO 10002-CM-0090-13001706) (TRADEMARK)

(2015/04315- 2015-GE-18972)

VKİ ve sol bacak kas arasinda $(r=, 584$, $\mathrm{p}<0.05$ ), pozitif orta düzeyde anlamlı bir ilişki,

VKİ ve sol bacak yağ arasında $(\mathrm{r}=, 774$, $\mathrm{p}<0.001$ ), pozitif yüksek düzeyde anlamlı bir ilişki,

Sağ kol kas ve sol kol kas arasında (r=,968, $\mathrm{p}<0.001)$, pozitif çok yüksek düzeyde anlam11 bir ilişki,

Sağ kol kas ve sağ bacak kas arasında (r=,946, $\mathrm{p}<0.001$ ), pozitif çok yüksek düzeyde anlam11 bir ilişki,

Sağ kol kas ve sol bacak kas arasında $(\mathrm{r}=, 953$, $\mathrm{p}<0.001$ ), pozitif çok yüksek düzeyde anlam11 bir ilişki,

Sağ kol yağ ve sol kol yağ arasında ( $r=, 904$, $\mathrm{p}<0.001$ ), pozitif çok yüksek düzeyde anlam11 bir ilişki,

Sağ kol yăg ve sağ bacak yağ arasında $(\mathrm{r}=, 678, \mathrm{p}<0.01)$, pozitif orta düzeyde anlam11 bir ilişki,

Sağ kol yağ ve sol bacak yağ arasında (r=,699, $\mathrm{p}<0.01$ ), pozitif orta düzeyde anlamlı bir ilişki,

Sol kol kas ve sağ bacak kas arasında $(\mathrm{r}=, 928$, $\mathrm{p}<0.001$ ), pozitif çok yüksek düzeyde anlam11 bir ilişki,

Sol kol kas ve sol bacak kas arasinda $(\mathrm{r}=, 928$, $\mathrm{p}<0.001$ ), pozitif çok yüksek düzeyde anlamlı bir ilişki,
Sol kol yağ ve sağ bacak yağ arasında (r=,578, $\mathrm{p}<0.05$ ), pozitif orta düzeyde anlamlı bir ilişki,

Sol kol yağ ve sol bacak yağ arasında $(\mathrm{r}=, 639$, $\mathrm{p}<0.01$ ), pozitif orta düzeyde anlamlı bir ilişki,

Sağ bacak kas ve sol bacak kas arasında $(\mathrm{r}=, 967, \mathrm{p}<0.001)$, pozitif çok yüksek düzeyde anlamlı bir ilişki,

Sağ bacak yağ ve sol bacak yağ arasında $(r=, 977, p<0.001)$, pozitif çok yüksek düzeyde anlamlı bir ilişki olduğu görülmüştür.

\section{SONUÇ}

Yapılan bu çalışmanın bulguları incelendiğinde üniversiteli kadın ve erkeklerde vücut kompozisyonu parametrelerine segmental olarak bakıldığında birçok anlamlı sonuçlara rastlanmıştır. Erkeklerde aerobik, anaerobik performans ve esneklik değerleri arasında pozitif ve negatif yönlü ilişkiler olduğu görülürken, kadınların aerobik, anaerobik performans ve esneklik değerleri parametrelerinin diğer değişkenler arasında pozitif ya da negatif yönlü hiçbir ilişkiye rastlanamadığ görülmüştür. Bunun nedeninin kadınların vücut yağ oranlarının daha fazla kas oranlarının daha düşük olmasından kaynaklandığı düşünülebilir. Ayrıca beden eğitimi ve spor yüksekokulu öğrencilerinin aerobik kapasitelerinin düşük olduğu görülmüş, bunun nedeninin ise araştırmaya katılan öğrencilerin son sınıf öğ- 


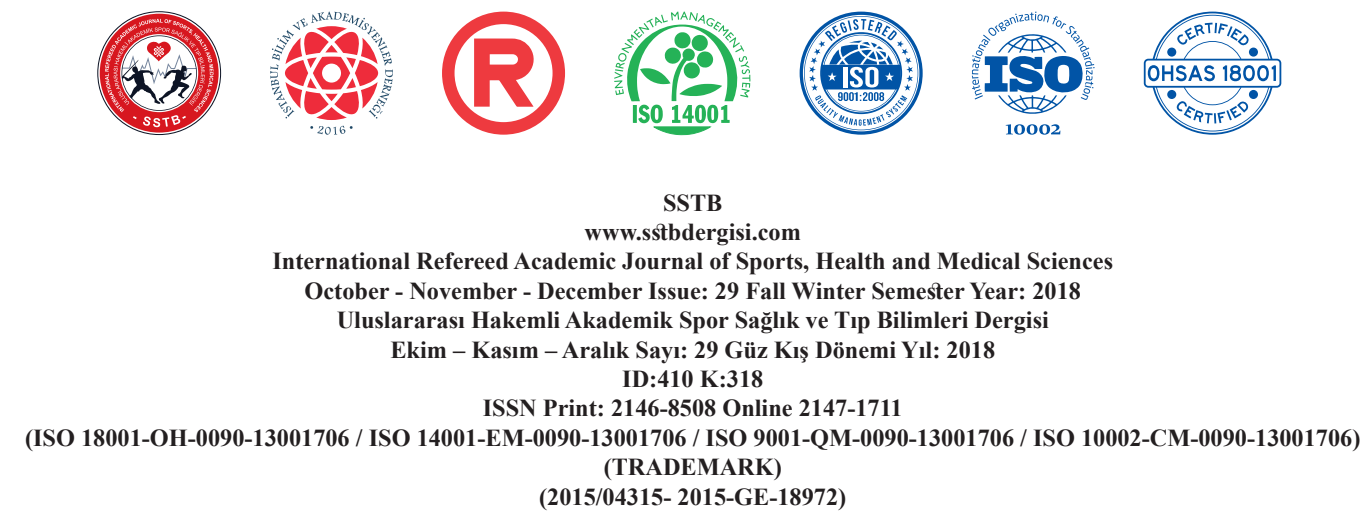

rencileri olduğundan kaynaklanabildiği düşünülmektedir.

Anaerobik veya aerobik çalışmayı kapsayan bütün spor branşları açısından vücuttaki yağlı dokuların fazla olması ve vücuttaki yağsız kas kütlesinin az olması performansı olumsuz etkileyen bir durum olarak görülmektedir (Falk ve Weinstein, 1996, Sternfeld, 2002).

$\mathrm{Bu}$ çalı̧̧mada kadınlarla erkekler arasında aerobik ve anaerobik performanslarnna bak1ldğında erkeklerin aerobik ve anaerobik kapasitelerinin daha yüksek olduğu, esneklik performansının ise kadınlarda biraz daha yüksek olduğu görülmüştür. Bu durum zaten kadınların fiziksel ve fizyolojik yapılarının erkeklerden farklı olmasından kaynaklanan bilinen bir durumdur. Erkeklerin konnektif dokularının kadınlara göre daha fazla olmasından dolayı kadınlar erkeklere göre daha esnektirler (Nalçakan, 2001).

Yine vücut segmentlerine göre sağ kol, sol kol, sağ bacak ve sol bacak kas ve yağ oranlarına bakıldığında da tüm parametrelerde kadınlarla erkekler arasında yağ ve kas oranları açısından belirgin farkl1lıklar görülmüştür.

Sternfeld ve diğerleri (2002) Amerika'da kadın ve erkeklerin vücut kompozisyonlarıyla fiziksel performanslarının ilişkisini incelemişlerdir. Katılımcıların yağsız kütle ve yağ kütlesi biolektrik impedans analiz cihazıyla belirlenmiştir. Bu çalışmada kadınların çalışma- mızın sonucunda olduğu gibi daha yüksek yağ kütlesine sahip oldukları söylenmiş̧tir. Daha yüksek yağ kütlesine sahip olanların daha yavaş yürüme hızına sahip olmaları arasında yüksek ilişki olduğu, daha yüksek yağsız kütleye sahip olanların ise sadece yüksek kavrama gücü arasında ilişki olduğu görülmüştür. Böylelikle bu çalışmada yağ kütlesinin fiziksel performans ve genel işleyişi bazı etki alanlarında olumsuz yönde etkilediği belirtilmiştir.

Bale (1991) genç kadın basketbol oyuncularının vücut kompozisyonlarını belirlemek ve basketbol performanslarıly ilişkilerini incelemek amacıyla yaptığı çalışmada antropometrik ölçümlerle somatotipleri ve vücut kompozisyonları hesaplanarak dikey sıçrama, anaerobik güç, sağ ve sol kavrama güçleri belirlenmiş̧tir. Vücut kompozisyonları ile belirlenen performans parametreleri arasında anlamlı bir sonuç bulunmamıştır. Çalışma sonucunda basketbolcuların vücut merkezlerinin alt ekstremiteye göre daha uzun olduğu, uzuv uzunluklarının uzun, kalça bölgesinin geniş ve kaslı olduğu görülmüştür.

Literatür incelendiğinde vücut kompozisyonu ile anaerobik güç ve özellikle dikey sıçrama arasında kuvvetli korelasyon olduğunu gösteren çalı̧̧malar bulunmaktadır (Ostojic ve diğ., 2006, Silvestre ve diğ., 2006, Almuzaini, 2007). Araştırmamız sonucunda da erkeklerin dikey sıçrama ve sol bacak kas arasında yük- 
International Refereed Academic Journal of Sports, Health and Medical Sciences

October - November - December Issue: 29 Fall Winter Semester Year: 2018

Uluslararası Hakemli Akademik Spor Sağlık ve Tıp Bilimleri Dergisi

Ekim - Kasım - Aralık Sayı: 29 Güz Kış Dönemi Yıl: 2018

ID:410 K:318

ISSN Print: 2146-8508 Online 2147-1711

(ISO 18001-OH-0090-13001706 / ISO 14001-EM-0090-13001706 / ISO 9001-QM-0090-13001706 / ISO 10002-CM-0090-13001706)

(TRADEMARK)

(2015/04315- 2015-GE-18972)

sek düzeyde anlamlı bir ilişki olduğu görülmüştür.

$\mathrm{Bu}$ çalışmaya benzer bir şekilde Karatosun diğerleri (1999)'un 19-25 yaş aralığına sahip 12 erkek Beden Eğitimi ve Spor Yüksekokul öğrencisi ile yaptıkları çalışmada Wingate testi uygulanmış, anaerobik güç ve kapasite ile vücut kompozisyonu arasındaki ilişki incelenmiştir. Çalışmanın sonucuna bakıldığında bacak kas kütlesi ile anaerobik güç ve kapasite sonuçları arasında anlamlı bir ilişki olduğu belirlenmiştir. Bu çalışmanın sonucu araştırmamız sonucundaki erkeklerde dikey sıçrama kapasitesinin bacak kas kütlesi ile anlamlı bir ilişki içermesi sonucuyla benzerlik göstermektedir.

Ziyagil ve diğerleri (1999)'un çalışmamıza benzer olarak fakat farklı yaş grubunda yaptıkları çalışma sonucunda 6-14 yaş grubu yaş grubu çocuklarda yaş, cinsiyet ve spor yapma alışkanlığının Sürat ve anaerobik güce etkisi incelenmiştir. Araştırmanın sonucunda boy uzunluğu, vücut ağırlığı, skinfold ölçümleri, 20 metre sürat koşusu, dikey sıçrama, anaerobik güç ve 10 metre koşu süratinin yaş ve cinsiyete bağlı değiştiği görülmüştür. Spor yapma faktörü açısından ise, çocuklarda 5 skinfold toplam değeri, 20 metre sürat koşusu ve bu koşunun sadece 2'nci 10 metrelik kısmındaki performansı etkilediği görülmüştür.
Markovic ve Jaric (2007) ise dikey sıçrama performansının vücut yapısı ve kas kuvvetiyle ilişkisine baktıklarında; vücut ağırlı̆̆ının kuvvet ve anaerobik gücü olumlu etkilediği fakat vücut ağırlı̆̆ının fazla olmasının dikey sıçrama yüksekliğini negatif olarak etkilediği sonucuna varmışlardır.

Arslan ve diğerleri (2009)'un çalışmasında elit kadın basketbol oyuncularında ve düzenli spor yapan kadınlarda vücut kompozisyonu ve esneklik ilişkisi incelenmiştir. Esneklik testi ile BIA ölçümlerinin korelasyon sonuçlarına göre elit düzey sporcularda sağ ve sol bacak yağ oranları (\%) başta olmak üzere, vücudun yağ oranı (\%), yağ ağırlığı $(\mathrm{kg})$, su oranı $(\%)$ ve beden yoğunluğu $(\mathrm{kg} / \mathrm{L})$ esneklik testi değerlerini etkilediği saptanmıştır. Bizim çalışmamızda üniversite öğrencilerinin esneklik testi değerlerinin vücut kompozisyonu ile arasında anlamlı bir ilişki olmadığ görülmüştür. Bunun nedeninin bu çalışmaya katılan katılımcıların elit sporcu olmamasından kaynaklanabileceği düşünülmektedir.

Çon ve arkadaşları (2012)'nin çalışmasında voleybolcuların esneklik ve vücut yağ yüzdesi değerlerinin dikey sıçrama performansına etkisi incelendiği çalışmada esnekliğin dikey sıçrama performansına olumlu katkı sağladı ̆̆1, buna karşın vücut yağ yüzdesi artışının esnekliği olumsuz yönde etkilediği söylenmiştir. 
International Refereed Academic Journal of Sports, Health and Medical Sciences October - November - December Issue: 29 Fall Winter Semester Year: 2018

Uluslararası Hakemli Akademik Spor Sağlık ve Tıp Bilimleri Dergisi Ekim - Kasım - Aralık Sayı: 29 Güz Kış Dönemi Yıl: 2018 ID:410 K:318

ISSN Print: 2146-8508 Online 2147-1711

(ISO 18001-OH-0090-13001706 / ISO 14001-EM-0090-13001706 / ISO 9001-QM-0090-13001706 / ISO 10002-CM-0090-13001706) (TRADEMARK)

Aslan ve diğerleri (2011)'in çalışmasında ise elit altı sporcularda vücut kompozisyonu, anaerobik performans ve sirt kuvveti arasındaki ilişki incelenmiştir. Yapılan araştırma sonucunda sporcuların vücut ağırlıkları, vücut yağ yüzdeleri, boy uzunlukları ve sırt kuvvetlerinin anaerobik performanslarında belirleyici rol aldığg tespit edilmiştir.

Barak ve diğerleri (2016)'nın çalışmasında ise elit altı kadın basketbol ve hentbolcularda vücut kompozisyonu, esneklik, anaerobik performans, kuvvet, denge ve alt-üst ekstremiteden elde edilen bazı değişkenlerin karş1laştırılması yapılmıştır. Sporcuların $10 \mathrm{~m}$ ve 20m koşu zamanı ve hızı arasında anlamlı farklılık bulunmamıştır. Ancak 10-20m mesafedeki hız değerleri incelendiğinde basketbolcuların hentbolculardan daha hızlı oldukları görülmüştür.

Suleiman ve diğerleri (2018)'in Nijerya'daki ilkokullarda yaptıkları çalıșmada karın kuvveti ile aerobik dayanıklılık ve esneklik parametreleri arasındaki ilişki incelenmiştir. $\mathrm{Bu}$ çalışmadaki aerobik kapasiteyi belirlemede bizim çalışmamızda olduğu gibi 12 dk koşyürü (Cooper) testi ve esneklik kapasitesini ölçmek için de yine çalışmamıza benzer şekilde otur-uzan testleri kullanılmıştır. Çalışma sonuçları incelendiğinde karın kuvveti ile esneklik ve aerobik dayanıklılık arasında önemli ölçüde farklılık olmadığ1 görülmüştür.
Literatürde konuyla ilgili yapılan araştırmalar incelendiğinde bu araştırmanın sonuçlarıyla benzerlikler görülebilmektedir. $\mathrm{Bu}$ araştırmanın sonucuna göre sporcularda vücut yağ ve kas oranlarının özellikle aerobik ve anaerobik performans kapasitelerini etkilediği söylenebilir. Ayrıca bu çalışmanın önemli bir özelliği olan vücut segmentlerine göre yağ ve kas oranlarının aerobik ve anaerobik performansı etkilediğinden dolayı sporcuların kol ve bacaklarını sağ ve sol olmak üzere eşit olarak kas gelişimini sağlamaya çalışmaları ve segmental olarak yağ oranlarını eşit düzeye getirmeye çalışmaları üst düzey performans için önemli bir durumdur. Bu konuyla ilgili yapılacak olan gelecekteki çalışmalara 1şık tutması amacıyla beden eğitimi ve spor yüksekokulu öğrencileri son sınıf öğrencileri üzerinde yapılmış olan bu çalışmaya benzer olarak sınıflar arası ve bölümler arasında karşılaştırmalar yapılarak daha farklı sonuçlar elde edilebilir. Ayrıca farklı branşlarla uğraşan sporcuların vücut segmentlerine göre yağ ve kas oranlarının farklı performans çıktılarıyla karşılaştırılmalarının yapılması önerilebilir.

\section{KAYNAKLAR}

ALMUZAINI, K.S., (2007). Muscle function in Saudi children and adolescents:relationship to anthropometric characteristics during growth. Pediatric exercise science, 19 (3): 319-333 
International Refereed Academic Journal of Sports, Health and Medical Sciences October - November - December Issue: 29 Fall Winter Semester Year: 2018 Uluslararası Hakemli Akademik Spor Sağlık ve Tıp Bilimleri Dergisi Ekim - Kasım - Aralık Sayı: 29 Güz Kış Dönemi Yıl: 2018 ID:410 K:318

ISSN Print: 2146-8508 Online 2147-1711

(ISO 18001-OH-0090-13001706 / ISO 14001-EM-0090-13001706 / ISO 9001-QM-0090-13001706 / ISO 10002-CM-0090-13001706) (TRADEMARK)

ARSLAN, E., YILMAZ, I., ARAS, ̈̈., (2009). Elit kadın basketbol oyuncularında ve düzenli spor yapan kadınlarda vücut kompozisyonu ve esneklik ilişkisi: pilot çalışma. Fizyoter Rehabil, 20 (2): 83-88

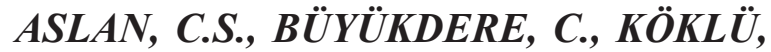
Y., ÖZKAN, A., ÖZDEMIR, F.N.Ş., (2011). Elit altı sporcularda vücut kompozisyonu, anaerobik performans ve sirt kuvveti arasındaki ilişkinin belirlenmesi. Uluslararası İnsan Bilimleri Dergisi, 8 (1): 1612-1628

BALE, P., (1991). Anthropometric, body composition and performance variables of young elite female basketball players. The Journal of Sports Medicine and Physical Fitness. 31(2): 173-177

BARAK, R., ÖZKAN, A., ÖZ, $\ddot{U}$., (2016). Elit altı kadın basketbol ve hentbolcularda alt ve üst ekstremiteden elde edilen bazı performans değişkenlerinin karşılaştırılmas1. 4 (Special Issue 3): 882-889

BAUMPARTER, R.N., CAMERON, C., ROCHE, A.F., (1998). Bioelectrical impedance for body composition. Am J Clin Nutr. 48 (1): 16-25

CICIOOGLU, I., GOKDEMIR, K., EROL, E., (1997). The effects of 8 weeks plyometric training program on vertical jump performanca and some physiological and physical paramaters of basketball players aged 14-15 years. Sports Science Journal. 2 (2): 11-23

ÇA ĞLAR, H.A., GÖKMEN, A., HAZIR, M., KUŞCU, Ö., (1997)., Erkek futbolcularda aerobik ve anaerobik güç ile hemoglobin, vücut yağ oranı ve vital kapasite arasındaki ilişki. Futbol Bilim ve Teknoloji Dergisi, 4 (1): 30-32

ÇON, M., AKYOL, P., TURAL, E., TAŞMEKTEPLIGIL, M.Y., (2012). Voleybolcuların esneklik ve vücut yağ yüzdesi değerlerinin dikey sıçrama performans1na etkisi. Selçuk Üniversitesi Beden Eğitimi ve Spor Bilim Dergisi, 14(2):202207

DIKKI, C.E., (1992). Validation of the vertical Toes: Sit and Research Measurement of Lumber Flexibility. Sports Science and Medicine 1 (1): 2-6

ELLIS, K.J., BELL, S.J., CHERTAW, G.M., (1999). Bioelectrical impedance methods in clinical research: A follow-up to the NIH technology assessment conference. Nutrition, 15 (1): 874- 880

ERDOĞAN, E., ÖZDEN, A., ÖZSOY, G., (2018). Farklı branşlardaki 10-14 yaş sporcuların bazı fiziksel ve fizyolojik parametrelerinin karşılaştırılması. Turki- 
International Refereed Academic Journal of Sports, Health and Medical Sciences October - November - December Issue: 29 Fall Winter Semester Year: 2018

Uluslararası Hakemli Akademik Spor Sağlık ve Tıp Bilimleri Dergisi Ekim - Kasım - Aralık Sayı: 29 Güz Kış Dönemi Yıl: 2018 ID:410 K:318

ISSN Print: 2146-8508 Online 2147-1711

(ISO 18001-OH-0090-13001706 / ISO 14001-EM-0090-13001706 / ISO 9001-QM-0090-13001706 / ISO 10002-CM-0090-13001706) (TRADEMARK)

ye Klinikleri Journal of Sports Sciences, 10(2): 66-72

FALK, B., WEINSTEIN, Y., (1996). A treadmill test of sprint running. Scand J. Med. Sci. Sport, 6(5): 259-264

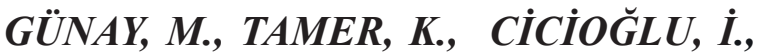
(2009). Spor fizyolojisi ve performans ölçümü. Gazi Kitabevi, Ankara

HEYWARD, V.H., (2006). Advanced Fitness assessment and Exercise Prescription, Fifth Edition, Human Kinetics, USA

HUGHES, J. M., LI, L., CHINN, S., RONA, R.J., (1997). Trends in growth in England and Scotland, 1972 to 1994. Archives of Disease in Childhood, 76(3): 182-189

JONATHAN, M., EUAN, A., (1997). A perspective on exercise, lactate, and the anaerobic threshold. Chest, 111:787-795

KARATOSUN, H., MURATLI, S., ERMAN, A., YAMAN, H., (1998). Anaerobik güç ve kapasite ile vücut kompozisyonu arasındaki ilişkinin incelenmesi. Hacettepe Üniversitesi, 5, 196

MARKOVIC, G., JARIC, S., (2007). Is vertical jump height a body size independent measure of muscle power? Journal of Sports Sciences, 25 (12): 1355-1363

MARTELLETTI, P., ANDREOLI, A., BERNONI, R.M., SABATO, F.D., DEL
BOLGIA, F., BALDI, A., et al., (1991). Bioelectrical impedance assay (bia) of total body composition in alcohol-1nduced migraine patients. Preliminary Report. Headache: The Journal of Head and Face Pain, 31(1): 41-45

MATHEWS, D.K., (1978). Measurement in physical education. Fifth Edition WB Saunders Company, USA

MIALICH, M.S., SICCHIERI, F.J.M., JORDAO, J.A.A., (2014)., Analysis of body composition: A critical review of the use of bioelectrical impedance analysis. Int J Clin Nutr, 2 (1):1-10

NAGLE, F.J., (1973). Physiological assessment of maximal performance. In: Wilmore JH. Edt. Exercise and Sport Sciences Reviews, New York: Academic Press, 313-339

NALÇAKAN, G.R., (2001).Voleybolcuların izokinetik kas kuvvetleri ile dikey sıçrama yükseklikleri arasındaki ilişki düzeyi. Yüksek Lisans Tezi, Ege Üniversitesi Sağlık Bilimleri Enstitüsü, İzmir

OSTOJIC, S.M., MAJIC, S., DIKIC, N., (2006). Profiling in basketball: physical and physiological characteristics of elite players. Journal of Strength and Conditioning Research, 20 (4): 740-744 
International Refereed Academic Journal of Sports, Health and Medical Sciences October - November - December Issue: 29 Fall Winter Semester Year: 2018

Uluslararası Hakemli Akademik Spor Sağlık ve Tıp Bilimleri Dergisi Ekim - Kasım - Aralık Sayı: 29 Güz Kış Dönemi Yıl: 2018 ID:410 K:318

ISSN Print: 2146-8508 Online 2147-1711

(ISO 18001-OH-0090-13001706 / ISO 14001-EM-0090-13001706 / ISO 9001-QM-0090-13001706 / ISO 10002-CM-0090-13001706) (TRADEMARK)

OZKARA, A., (2002) Futbolda testler. İlksan Matbaacılık, Ankara

SALLES, P.G.C.M., VASCONCELLOS, F.V.A., SALLES, F.F.C.M., FONSECA, R.T., DANTAS, E.H.M., (2012). Validity and reproducibility of the sargent jump test in the assessment of explosive strength in soccer players. Journal of $\mathrm{Hu}-$ man Kinetics, 33 (1): 115-121

SILVESTRE, R., WEST, C., MARESH, C.M., KRAEMER, W., (2006). Body composition and physical performance in men s soccer: a study of a national collegiate athletic association division 1 team J. Strength \& Cond. Res. 20 (1): 177-183

\section{SINIRKAVAK, G., DAL, U., ÇETINKAYA,} $\ddot{O}$. , (2004). Elit sporcularda vücut kompozisyonu ile maksimal oksijen kapasitesi arasındaki ilişki. C. Ü. Tıp Fakültesi Dergisi 26 (4): 171-176

STERNFELD, S., NGO, L., SATARIANO, W.A., TAGER, I.B., (2002). Associations of body composition with physical performance and self-reported functional limitation in elderly men and women. American Journal of Epidemiology, 156 (1):110-121
SULEIMAN, U.O., EZE, E.D., TSAURI, Y.M., ADEWALE, J.B., ABDULLAHi, Y., (2018). Comparison of physical fitness of rural, semi-urban and urban of primary school children in their abdominal strength, flexibility and cardio-respiratory endurance in federal capital territory, Nigeria. MOJ Sports Med, 2 (1): 00043

TAMER, K., (2000). Sporda fiziksel-fizyolojik performansın ölçülmesi ve değerlendirilmesi, 2. Baskı, Bağırgan Yayınevi, Ankara.

YILDIZ, S.A., (2012). Aerobik ve anaerobik kapasitenin anlamı nedir? Solunum dergisi, 14(1): 1-8

ZIYAGIL, M.A., ZORBA, E., BOZATLI, S., IMAMOĞLU, O., (1999). 6-14 yaş grubu çocuklarda yaş, cinsiyet ve spor yapma alışkanlığının sürat ve anaerobik güce etkisi. CBÜ Beden Eğitimi ve Spor Bilimleri Dergisi, 3(3): 9-18

ZORBA, E., SAYGIN, Ö., (2009). Fiziksel aktivite ve fiziksel uygunluk.(2. Bask1). İstanbul: İnceler Ofset, 205-217 


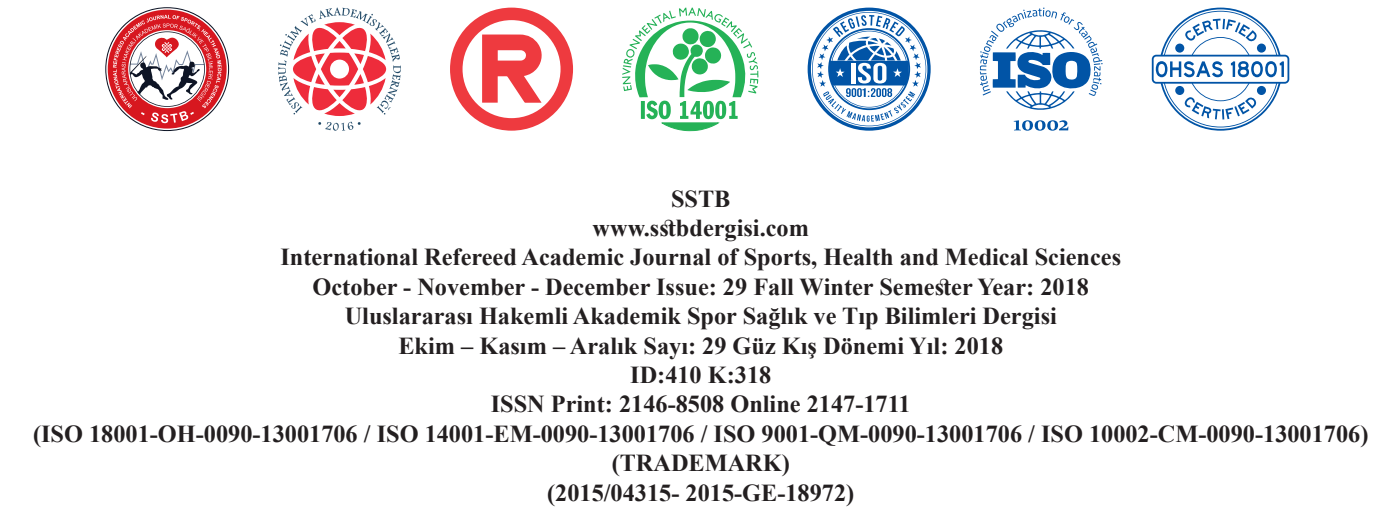

\section{EXTENDED ABSTRACT}

Introduction: Today, bioelectrical impedance analysis is the most advanced and widely used techniques to determine body composition. BIA measurement is a more practical and inexpensive method compared to other body composition measurement methods (Baumparter et.al., 1998; Ellis et. al., 1999). Segmental evaluation of body composition is a very important evaluation in order to see the effects of exercise, disease or trauma (Hughes, 1997). Anthropometric properties which are closely related with the physiological activity of human organism can be said to be among the factors determining success in sport (Sinırkavak et al., 2004, Zorba $\&$ Saygin, 2009). Aerobic capacity can be defined as the capacity to deliver the oxygen to be used to create the necessary energy during exercise (Y1ld1z, 2012). Anaerobic capacity is defined as the work capacity of skeletal muscles using anaerobic energy transfer systems during maximal and submaximal physical activity (Jonathan, 1997). Aerobic and anaerobic capacity influenced by many factors as age, gender, genetic factors, physiological characteristics, level of training and body composition (Çağlar et al., 1997, Yıldız, 2012). Aerobic capacity and anaerobic capacity are important characteristics that affect performance in many sports branches. These features are genetically related to the level and the training of the human. These motoric features can be evaluated by determining body compositions and by segmental examination. In the light of this information, it was aimed to determine the body muscle and fat ratios of body and sports body students in terms of aerobic, anaerobic and resilience performances. Aim: The aim of this study was to determine the relationship between aerobic, anaerobic and flexbility properties of body fat and muscle ratios according to body segments of physical education and sports students. Material and method: A total of 31 students (18 female and 13 male) were studying at Ahi Evran University School of Physical Education and Sports participated in the study. The body compositions of the students were determined by bioelectric impedance (BIA) analysis. In order to determine aerobic capacity Cooper test, to determine the anaerobic capacities of 30 meters sprint test and vertical jump test, and to determine the flexibility sit-reach test was used in the study. Data obtained from this study were analyzed by using SPSS 22.0 package program for Windows and descriptive statistics and Spearman Correlation analysis were performed. Results: When the findings of this study were examined, it was seen that there were many significant results in terms of body composition parameters in university women and men as a segmental. When the findings were examined, a high level of negative correlation was found between the vertical jump and the left leg muscle $(r=-, 718, p<0.01)$ and there was 
International Refereed Academic Journal of Sports, Health and Medical Sciences

October - November - December Issue: 29 Fall Winter Semester Year: 2018

Uluslararası Hakemli Akademik Spor Sağlık ve Tıp Bilimleri Dergisi

Ekim - Kasım - Aralık Sayı: 29 Güz Kış Dönemi Yıl: 2018 ID:410 K:318

ISSN Print: 2146-8508 Online 2147-1711

(ISO 18001-OH-0090-13001706 / ISO 14001-EM-0090-13001706 / ISO 9001-QM-0090-13001706 / ISO 10002-CM-0090-13001706) (TRADEMARK)

(2015/04315- 2015-GE-18972)

a moderate positive correlation between $30 \mathrm{~m}$ sprint and muscle mass $(\mathrm{r}=642, \mathrm{p}<0.05)$. There was no significant relationship was found between performance parameters and body segments for women. When the right arm, left arm, right leg and left leg muscle and fat ratios were examined according to body segments, there were significant differences in fat and muscle ratios between women and men in all parameters. Conclusion: When the researches in the literature are examined, similarities can be seen with the results of this research. In this study, aerobic and anaerobic performances of men and women were higher and aerobic and anaerobic capacities were higher and flexibility performance was higher in women. This is due to the fact that women's physical and physiological structures are different from men. As a result, there was a relationship between aerobic and anaerobic capacities of muscle masses and fat percentages of males according to body segments. When the findings of this study were examined, it was seen that there were many significant results in terms of body composition parameters in university women and men as a segmental. There were positive and negative correlations between aeorobic, anaerobic performance and resilience values in males and there were no positive or negative correlations among the other variables. When the muscle and fat ratios were examined according to the body segments in women, it was possible to say that the muscle ratios were low and the fat ratios were high and therefore the aerobic and anaerobic capacities were low. In addition, body and fat segments, which is an important feature of this study because of the effects of fat and muscle aerobic and anaerobic performance of the athletes because of the arms and legs of the right and left to work equally to improve muscle development and segmental fat to work to bring equal levels of an important level for high performance. 